\title{
Tuning Nanoparticle Structure and Surface Strain for Catalysis Optimization
}

\author{
Sen Zhang, ${ }^{\dagger} \mathrm{Xu}$ Zhang, ${ }^{\ddagger}$ Guangming Jiang, ${ }^{\dagger}$ Huiyuan Zhu, ${ }^{\dagger}$ Shaojun Guo, ${ }^{\dagger}$ Dong Su, ${ }^{\S}$ Gang Lu, \\ and Shouheng Sun ${ }^{* \dagger}$ \\ ${ }^{\dagger}$ Department of Chemistry, Brown University, Providence, Rhode Island 02912, United States \\ ${ }^{\ddagger}$ Department of Physics and Astronomy, California State University-Northridge, Northridge, California 91330, United States \\ ${ }^{\S}$ Center for Functional Nanomaterials, Brookhaven National Laboratory, Upton, New York 11973, United States
}

\section{Supporting Information}

\begin{abstract}
Controlling nanoparticle (NP) surface strain, i.e. compression (or stretch) of surface atoms, is an important approach to tune NP surface chemistry and to optimize NP catalysis for chemical reactions. Here we show that surface Pt strain in the core/shell FePt/Pt NPs with Pt in three atomic layers can be rationally tuned via core structural transition from cubic solid solution [denoted as face centered cubic (fcc)] structure to tetragonal intermetallic [denoted as face centered tetragonal (fct)] structure. The high activity observed from the fct-FePt/Pt NPs for oxygen reduction reaction (ORR) is due to the release of the overcompressed Pt strain by the fct-FePt as

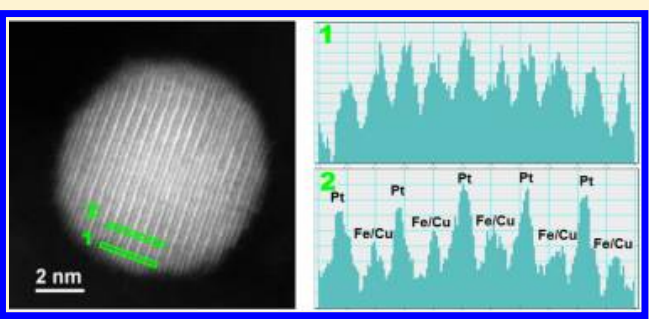
suggested by quantum mechanics-molecular mechanics (QM-MM) simulations. The Pt strain effect on ORR can be further optimized when $\mathrm{Fe}$ in $\mathrm{FePt}$ is partially replaced by $\mathrm{Cu}$. As a result, the fct-FeCuPt/Pt NPs become the most efficient catalyst for ORR and are nearly 10 times more active in specific activity than the commercial Pt catalyst. This structure-induced surface strain control opens up a new path to tune and optimize NP catalysis for ORR and many other chemical reactions.
\end{abstract}

\section{INTRODUCTION}

In the search for highly efficient nanoparticle (NP) catalysts for chemical conversions, one often explores NPs' sizes, shapes, and compositions as important parameters to tune NPs' catalytic properties. $^{1-5}$ It has become increasingly important to rationalize NP parameters with catalysis in order to provide predictable models for catalyst design and optimization. ${ }^{6-10}$ NPs based on platinum $(\mathrm{Pt})$ have constantly been the subject of the studies due to their unique properties shown in catalyzing many chemical reactions, including the oxygen reduction reaction (ORR), an important cathodic reaction used in low-temperature polymer electrolyte membrane fuel cells and metal-air batteries. ${ }^{11-20}$ Recent studies on ORR have indicated that $\mathrm{Pt}-\mathrm{Pt}$ bond compression, and the resultant $\mathrm{d}$ band down-shift, weakens the bonding between $\mathrm{Pt}$ and oxygenated species (O) and increases catalytic activity for ORR. $^{21-27}$ Density functional theory (DFT) calculations further suggest that $\mathrm{Pt}-\mathrm{O}$ binding energy $\left(E_{\mathrm{O}}\right)$, a key "descriptor" to measure the adsorption/desorption of oxygenated species, should be $0.2 \mathrm{eV}$ higher $\left(\Delta E_{\mathrm{O}}=0.2 \mathrm{eV}\right)$ than the corresponding value on the $\operatorname{Pt}(111)$ surface in order for a $\mathrm{Pt}$ catalyst to achieve optimal ORR activity. ${ }^{28-31}$ An unanswered, yet extremely important, question related to Ptbased ORR catalysis is if indeed there exists a form of Pt NP catalyst whose oxygen binding energy coincides with the optimal $\Delta E_{\mathrm{O}}$ value for which ORR catalytic efficiency is maximized.
Here we report a strategy to tune and optimize ORR catalysis of multimetallic core/shell NPs by controlling the crystal structure of the core and surface strain of the shell. In previous studies on ORR catalysis, Pt alloy NPs are the universal choice of the catalyst and are often in chemically disordered solid solution structure. Chemically ordered intermetallic structure is rarely considered as a factor due to the difficulty in obtaining such a structure without sacrificing other NP parameters, such as size, shape, and composition, ${ }^{32-35}$ making it impossible to identify the true nature of the catalytic enhancement. We have synthesized monodisperse FePt alloy NPs with controlled sizes and compositions. ${ }^{36-38}$ We noticed that when these alloy NPs were deposited on the carbon support, they could withstand high-temperature treatment without showing any sign of aggregation or sintering, and their solid solution structure [often denoted as face centered cubic (fcc) structure] could be converted to tetragonal intermetallic structure [often denoted as face centered tetragonal (fct) structure]. More importantly, electro-anodization of these FePt NPs in $0.1 \mathrm{M} \mathrm{HClO}_{4}$ led to stable core/shell $\mathrm{FePt} / \mathrm{Pt} \mathrm{NPs}$ with $\mathrm{Pt}$ only in about three atomic layers. The fct-core/shell catalyst showed much enhanced catalytic efficiency for ORR, and this enhancement was attributed to more favored release of $\mathrm{Pt}$ strain in the fct$\mathrm{FePt} / \mathrm{Pt}$ than in the fcc-FePt/Pt, as calculated by the quantum mechanics-molecular mechanics (QM-MM) simulations. The

Received: March 25, 2014

Published: May 6, 2014 
simulations also suggested that by partially replacing $\mathrm{Fe}$ with $\mathrm{Cu}$ and forming fct-FeCuPt/Pt NPs, the overcompressed strain in Pt shell could be further released with $\Delta E_{\mathrm{O}}$ reaching $0.22 \mathrm{eV}$, very close to the predicted optimal value at $0.20 \mathrm{eV}$. Experimentally, the fct-FeCuPt/Pt NPs were indeed the most efficient catalyst for ORR, and their specific activity was nearly 10 times higher than that of the commercial Pt catalyst (Fuel Cells Store).

\section{EXPERIMENTAL SECTION}

2.1. Chemicals and Materials. Oleylamine (>70\%), oleic acid, 1octadecene, $\mathrm{Pt}(\mathrm{acac})_{2}$ ( $\mathrm{acac}=$ aceylacetonate $), \mathrm{Cu}(\mathrm{acac})_{2}$, iron pentacarbonyl $\left[\mathrm{Fe}(\mathrm{CO})_{5}\right]$, hexane, 2-propanol, ethanol, and Nafion (5\%) were all purchased from Sigma-Aldrich and used without further purification. The commercial $\mathrm{Pt}(20 \%$ mass loading on carbon with a diameter of 2.5-3.5 nm) catalyst was obtained from Fuel Cell Store.

2.2. Synthesis of FePt NPs. Under a gentle flow of $\mathrm{N}_{2}, 1$ octadecene $(10 \mathrm{~mL})$, oleic acid $(1.28 \mathrm{~mL}, 4 \mathrm{mmol})$, oleylamine $(1.36$ $\mathrm{mL}, 4 \mathrm{mmol})$, and $\mathrm{Pt}(\mathrm{acac})_{2}(0.2 \mathrm{~g}, 0.5 \mathrm{mmol})$ were mixed in a fournecked flask. The mixture was magnetically stirred and heated to 120 ${ }^{\circ} \mathrm{C}$ to generate a light yellow solution. Under a $\mathrm{N}_{2}$ blanket, $0.16 \mathrm{~mL}$ $(1.23 \mathrm{mmol})$ of $\mathrm{Fe}(\mathrm{CO})_{5}$ was added into the solution. The solution was heated to $220{ }^{\circ} \mathrm{C}$ at a rate of about $3{ }^{\circ} \mathrm{C} / \mathrm{min}$ and kept at this temperature for $1 \mathrm{~h}$ before it was cooled to room temperature. The NPs were separated by adding 2-propanol $(50 \mathrm{~mL})$, followed by centrifugation ( $8500 \mathrm{rpm}, 8 \mathrm{~min}$ ). The NPs were further purified by dispersing into hexane $(20 \mathrm{~mL})$ and centrifugation $(5000 \mathrm{rpm}, 8 \mathrm{~min})$ to remove any undispersed precipitates. The product was precipitated out by adding ethanol $(50 \mathrm{~mL})$, the mixture was centrifuged $(8500$ $\mathrm{rpm}, 8 \mathrm{~min}$ ), and the product was redispersed in hexane. The synthesis yielded $\mathrm{Fe}_{51} \mathrm{Pt}_{49} \mathrm{NPs}$.

Under the same condition and when $1.07 \mathrm{mmol}$ of $\mathrm{Fe}(\mathrm{CO})_{5}$ was used in the synthesis, $\mathrm{Fe}_{42} \mathrm{Pt}_{58} \mathrm{NPs}$ were obtained. In the presence of $1.07 \mathrm{mmol}$ of $\mathrm{Fe}(\mathrm{CO})_{5}$ and at $200{ }^{\circ} \mathrm{C}$ (or $180{ }^{\circ} \mathrm{C}$ ), $\mathrm{Fe}_{33} \mathrm{Pt}_{67}$ (or $\left.\mathrm{Fe}_{27} \mathrm{Pt}_{73}\right)$ NPs were separated.

2.3. Synthesis of FeCuPt NPs. FeCuPt NPs were prepared by a seed mediated growth of $\mathrm{Cu}$ over FePt NPs followed by $\mathrm{Cu}$ diffusion into FePt. In a typical synthesis, 1-octadecene $(15 \mathrm{~mL})$, oleylamine $(2$ $\mathrm{mL})$, and $\mathrm{Cu}(\mathrm{acac})_{2}(14 \mathrm{mg})$ were mixed in a four-necked flask. The mixture was magnetically stirred and heated to $80{ }^{\circ} \mathrm{C}$ to generate a bluish green solution under a gentle flow of $\mathrm{N}_{2}$. Then $40 \mathrm{mg}$ of $\mathrm{Fe}_{42} \mathrm{Pt}_{58} \mathrm{NPs}$ (hexane dispersion) was added into the solution. Upon the evaporation of hexane, the solution was heated to $240{ }^{\circ} \mathrm{C}$ at a rate of about $3{ }^{\circ} \mathrm{C} / \mathrm{min}$ and kept at this temperature for $1 \mathrm{~h}$ before it was cooled to room temperature. The NPs were separated by adding 2propanol $(50 \mathrm{~mL})$, followed by centrifugation $(8500 \mathrm{rpm}, 8 \mathrm{~min})$. The NPs were further purified by dispersing into hexane $(20 \mathrm{~mL})$ and centrifugation (5000 rpm, $3 \mathrm{~min}$ ) to remove any undispersed precipitates. The product was precipitated out by adding ethanol $(50 \mathrm{~mL})$, the mixture was centrifuged $(8500 \mathrm{rpm}, 8 \mathrm{~min})$, and the product eas redispersed in hexane. The synthesis yielded $\mathrm{Fe}_{38} \mathrm{Cu}_{15} \mathrm{Pt}_{47}$ NPs.

Under the same reaction condition, $18 \mathrm{mg}$ of $\mathrm{Cu}(\mathrm{acac})_{2}$ and $40 \mathrm{mg}$ of $\mathrm{Fe}_{34} \mathrm{Pt}_{66}$ seeds led to the formation of $\mathrm{Fe}_{25} \mathrm{Cu}_{23} \mathrm{Pt}_{52} \mathrm{NPs} .24 \mathrm{mg}$ of $\mathrm{Cu}$ (acac) $)_{2}$ and $40 \mathrm{mg}$ of $\mathrm{Fe}_{27} \mathrm{Pt}_{73}$ seeds yielded $\mathrm{Fe}_{19} \mathrm{Cu}_{35} \mathrm{Pt}_{46} \mathrm{NPs}$.

2.4. Catalyst Preparation and NP Structural Control. The assynthesized NPs and Ketjen-300 J carbon at a weight ratio of 1:2 were mixed in $20 \mathrm{~mL}$ of hexane and sonicated for $1 \mathrm{~h}$ to deposit NPs on carbon (C-NPs). The product was separated by centrifugation (8500 $\mathrm{rpm}, 3 \mathrm{~min}$ ). The $\mathrm{C}-\mathrm{NPs}$ were dried under ambient conditions and annealed at different temperatures for $1 \mathrm{~h}$ in a gas flow of $\mathrm{Ar}+5 \% \mathrm{H}_{2}$ to control the NPs structures. The product was then resuspended in a mixture of deionized water, 2-propanol, and Nafion $(\mathrm{v} / \mathrm{v} / \mathrm{v}=4 / 1$ / $0.05)$. Twenty microliters of catalyst ink $(2 \mathrm{mg} / \mathrm{mL})$ was deposited on the working electrode (glassy carbon rotating disk electrode, GC$\mathrm{RDE}$ ) that was polished prior to catalyst deposition by 0.1 and 0.05 $\mu \mathrm{m}$ alumina powder and rinsed by sonication in ethanol and in deionized water. The catalyst was dried in ambient condition.
2.5. Characterizations. X-ray diffraction (XRD) patterns of the NPs were collected on a Bruker AXS D8-Advanced diffractometer with $\mathrm{Cu} \mathrm{K} \alpha$ radiation $(\lambda=1.5418 \AA)$. Transmission electron microscopy (TEM) images were acquired from a Philips CM 20 operating at 200 $\mathrm{kV}$. Scanning transmission electron microscopy (STEM) analyses were carried out on a Hitachi HD2700C $(200 \mathrm{kV})$ with a probe aberration corrector, at the Center for Functional Nanomaterials, Brookhaven National Lab. The electron energy loss spectroscopy (EELS) line-scan was obtained by a high-resolution Gatan-Enfina ER with a probe size of $1.3 \AA$. A power law function was used for EELS background subtraction. TEM and high-resolution TEM (HRTEM) samples were prepared by depositing a single drop of diluted NPs dispersion on amorphous carbon-coated copper grids. The inductively coupled plasma-atomic emission spectroscopy (ICP-AES) measurements were carried on a JY2000 Ultrace ICP atomic emission spectrometer equipped with a JY AS 421 autosampler and $2400 \mathrm{~g} / \mathrm{mm}$ holographic grating. Electrochemical measurements were performed on an Autolab 302 potentiostat with glassy carbon rotating disk ( $5 \mathrm{~mm}$ in diameter) as a working electrode, $\mathrm{Ag} / \mathrm{AgCl}(4 \mathrm{M} \mathrm{KCl})$ as a reference electrode, and platinum wire as a counter electrode.

2.6. Electrochemical Measurements. The NPs were first subject to cyclic voltammetry (CV) scans between -0.2 and $1.0 \mathrm{~V}$ (vs Ag/ $\mathrm{AgCl})$ at $100 \mathrm{mV} / \mathrm{s}$ in $\mathrm{N}_{2}$-saturated $0.1 \mathrm{M} \mathrm{HClO}_{4}$ until a stable $\mathrm{CV}$ was obtained (150 scans for the fcc-FePt and 300 scans for the fct$\mathrm{FePt} \mathrm{NPs}$ ). Once the core/shell $\mathrm{FePt} / \mathrm{Pt} \mathrm{NPs}$ were obtained, their CVs were recorded at a scan rate of $50 \mathrm{mV} / \mathrm{s}$ in $\mathrm{N}_{2}$-saturated $0.1 \mathrm{M}$ $\mathrm{HClO}_{4}$ and were used to estimate electrochemically active surface area (ECASA). ORR polarization curves were recorded by linear-sweep voltammetry (LSV) at a scan rate of $10 \mathrm{mV} / \mathrm{s}$ in $\mathrm{O}_{2}$-saturated $0.1 \mathrm{M}$ $\mathrm{HClO}_{4}$ with the GC-RDE rotating at $1600 \mathrm{rpm}$.

2.7. QM-MM Simulations. Core/shell NPs are modeled by $8 \mathrm{~nm}$ cuboctahedrons with eight (111) facets and six (100) facets. The NP consists of an fcc-Pt shell (with three atomic layers) and a FePt or $\mathrm{FeCuPt}$ core. $\Delta E_{\mathrm{O}}$ relative to the flat $\mathrm{Pt}(111)$ surface is determined by placing an $\mathrm{O}$ atom at the hollow site on the (111) facet of fcc-Pt, following

$$
\begin{aligned}
\Delta E_{\mathrm{O}}= & \left(E_{\mathrm{QM} / \mathrm{MM}}[\mathrm{NP}+\mathrm{O}]-E_{\mathrm{QM} / \mathrm{MM}}[\mathrm{NP}]\right) \\
& -\left(E_{\mathrm{QM}}[\mathrm{Pt}(111)+\mathrm{O}]-E_{\mathrm{QM}}[\mathrm{Pt}(111)]\right)
\end{aligned}
$$

where $E_{\mathrm{QM} / \mathrm{MM}}[\mathrm{NP}+\mathrm{O}]$ and $E_{\mathrm{QM} / \mathrm{MM}}[\mathrm{NP}]$ are total energies of NPs with and without $\mathrm{O}$ adsorbate, respectively, from QM-MM calculations. $E_{\mathrm{OM}}[\mathrm{Pt}(111)+\mathrm{O}]$ and $E_{\mathrm{OM}}[\mathrm{Pt}(111)]$ are the total energies of the flat $\mathrm{Pt}(111)$ surface with and without the absorbed $\mathrm{O}$ atom calculated by DFT. The QM-MM simulation details are provided in the Supporting Information (Text S1).

2.8. Equilibrium Lattice Constants of FePt and FeCuPt from DFT Calculations. A periodic supercell consisting of 108 atoms is used to determine the atomic structure of $\mathrm{FePt}$ or $\mathrm{FeCuPt}$ cores. For fcc- $\mathrm{Fe}(\mathrm{Cu}) \mathrm{Pt}, \mathrm{Pt}$ and $\mathrm{Fe}(\mathrm{Cu})$ atoms are randomly arranged in the supercell. For fct- $\mathrm{Fe}(\mathrm{Cu}) \mathrm{Pt}$, alternating $\mathrm{Pt}$ and $\mathrm{Fe}(\mathrm{Cu})$ layers are arranged in the supercell. $\mathrm{Fe}$ and $\mathrm{Cu}$ atoms are randomly arranged in the $\mathrm{Fe}(\mathrm{Cu})$ atom layers. All atoms are fully relaxed under constant zero pressure by using the DFT calculations, and details are provided in the Supporting Information (Text S2).

\section{RESULTS AND DISCUSSION}

The fcc-FePt NPs were synthesized by the reduction of platinum acetylacetonate, $\mathrm{Pt}(\mathrm{acac})_{2}$, and thermal decomposition of iron pentacarbonyl, $\mathrm{Fe}(\mathrm{CO})_{5}$, in the presence of oleylamine and oleic acid as reported. ${ }^{38}$ This simple mixing and heating approach led to the formation of monodisperse $\mathrm{FePt}$ NPs with a high yield ( $\geq 97 \%$ based on $\mathrm{Pt}$ ) and could be scaledup for mass production. $\mathrm{Fe} / \mathrm{Pt}$ compositions were controlled by $\mathrm{Fe}(\mathrm{CO})_{5} / \mathrm{Pt}(\mathrm{acac})_{2}$ molar ratios and reaction temperatures and were analyzed by inductively coupled plasma-atomic emission spectroscopy (ICP-AES). Transmission electron microscopy (TEM) images show that the as-synthesized fcc-Fe ${ }_{51} \mathrm{Pt}_{49} \mathrm{NPs}$ 
are cubelike with lateral dimension of $8.5 \pm 0.5 \mathrm{~nm}$ (Figure 1a; TEM images of the other Pt-rich FePt NPs of similar sizes are

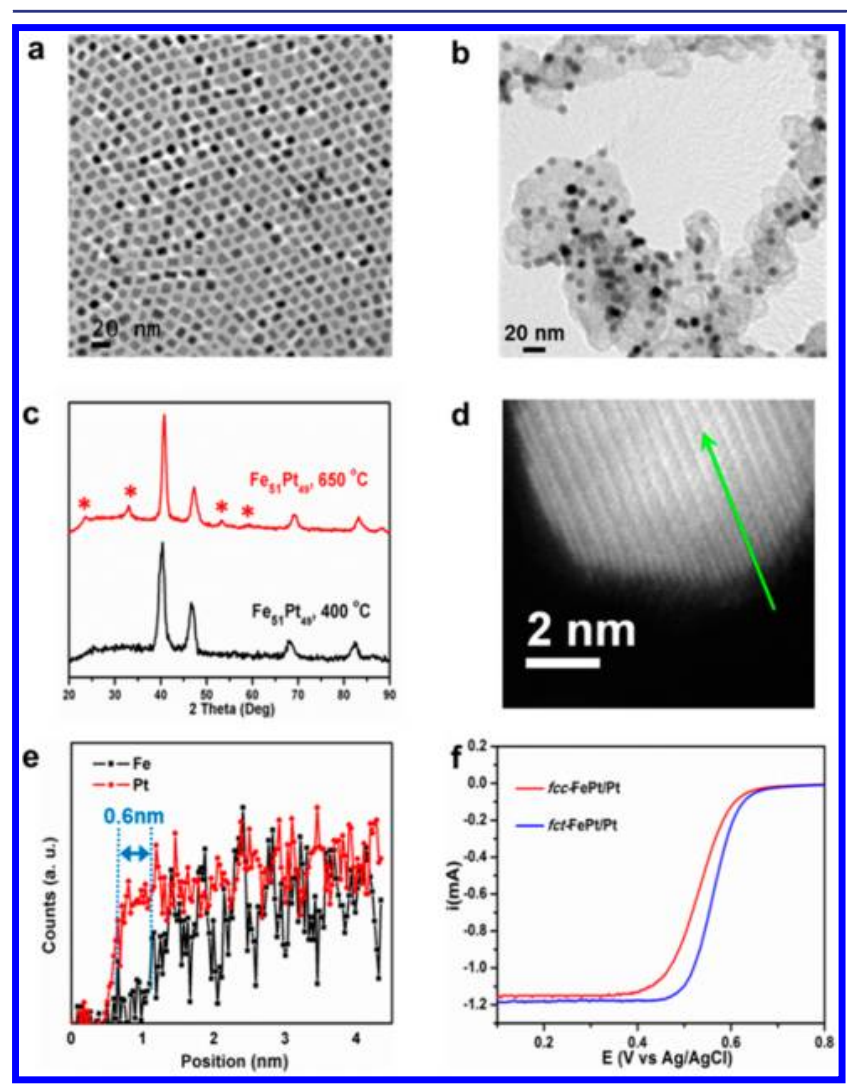

Figure 1. (a, b) TEM images of the as-synthesized fcc-Fe ${ }_{51} \mathrm{Pt}_{49} \mathrm{NPs}$ (a) and the $\mathrm{C}-\mathrm{Fe}_{51} \mathrm{Pt}_{49}$ NPs annealed at $650{ }^{\circ} \mathrm{C}$ (b). (c) XRD patterns of the $\mathrm{C}-\mathrm{Fe}_{51} \mathrm{Pt}_{49} \mathrm{NPs}$ annealed at 400 and $650{ }^{\circ} \mathrm{C}$ (stars denote the typical peaks characteristic of fct-FePt). (d, e) HAADFSTEM image (d) and STEM-EELS line scan (e) of an electrochemically dealloyed $\mathrm{C}-\mathrm{fct}-\mathrm{Fe}_{51} \mathrm{Pt}_{49} \mathrm{NP}$, forming $\mathrm{C}-\mathrm{fct}-\mathrm{FePt} / \mathrm{Pt}$. The arrow indicates the line scan position. (f) ORR polarization curves of the fccand fct-FePt/Pt. The ORR polarization curves were obtained in $\mathrm{O}_{2}$ saturated $0.1 \mathrm{M} \mathrm{HClO}_{4}$ with the working disk electrode rotating at $1600 \mathrm{rpm}$ and a potential scan rate at $10 \mathrm{mV} / \mathrm{s}$.

shown in Figure S1a-c, of the Supporting Information). The fcc-FePt NPs were deposited on Ketjen carbon (C), similar to what has been reported, ${ }^{39}$ and are denoted as $\mathrm{C}-\mathrm{FePt}$ NPs. The $\mathrm{C}-\mathrm{FePt}$ NPs were annealed in $95 \% \mathrm{Ar}+5 \% \mathrm{H}_{2}$ for $1 \mathrm{~h}$ at temperatures from 400 to $700{ }^{\circ} \mathrm{C}$, and $650{ }^{\circ} \mathrm{C}$ was found to be the optimum temperature to convert fcc- $\mathrm{Fe}_{51} \mathrm{Pt}_{49}$ to fct-Fe ${ }_{51} \mathrm{Pt}_{49}$ without causing obvious NP aggregation/sintering, as shown in Figures $1 b, c$ and Figure S2 (Supporting Information) (other Ptrich FePt NPs could not be converted into the fct structure under this annealing condition). After annealing, both fcc- and fct-FePt NPs adopted the same thermodynamically more stable polyhedral shape.

The $\mathrm{C}-\mathrm{fcc}_{\mathrm{f}}-\mathrm{Fe}_{51} \mathrm{Pt}_{49}$ (preannealed at $400{ }^{\circ} \mathrm{C}$ ) and $\mathrm{C}-$ fct$\mathrm{Fe}_{51} \mathrm{Pt}_{49}$ NPs were deposited on GC-RDE and were subject to a potential scan between -0.2 and $1.0 \mathrm{~V}$ (vs $\mathrm{Ag} / \mathrm{AgCl}$ ) in the $\mathrm{N}_{2}$ saturated $0.1 \mathrm{M} \mathrm{HClO}{ }_{4}$ solution until a stable currentpotential curve was obtained. The process oxidized and dissolved the surface $\mathrm{Fe}$, leading to the formation of stable core/shell FePt/Pt NPs. The core/shell structure was characterized by aberration-corrected high-angle annular dark field scanning transmission electron microscopy (HAADF-
STEM) and STEM-electron energy loss spectroscopy (STEMEELS), as shown in Figures $1 \mathrm{~d}$,e and S3 (Supporting Information). Both the fcc- and fct- $\mathrm{Fe}_{51} \mathrm{Pt}_{49} \mathrm{NPs}$ show a Pt shell of $\sim 0.6 \mathrm{~nm}$ (ca. three atomic layers) with the FePt cores maintaining their structures. In addition, the alternate $\mathrm{Pt}$ and $\mathrm{Fe}$ layers in the fct-FePt core region are clearly indicated by their brighter (high $Z$ contrast for $\mathrm{Pt}$ ) and darker (low $Z$ contrast for $\mathrm{Fe})$ contrasts. ${ }^{40}$ In the core/shell NPs, the Fe/Pt composition is stabilized at $25 / 75$ in the fcc-FePt/Pt and $26 / 74$ in the fct$\mathrm{FePt} / \mathrm{Pt}$, indicating that the core/shell NPs have the same $\mathrm{Fe} /$ Pt ratios.

The electrochemically active surface area (ECASA) of the $\mathrm{FePt} / \mathrm{Pt}$, as well as the commercial Pt $(2.5-3.5 \mathrm{~nm} \mathrm{Pt} \mathrm{NPs}$; Figure S4, Supporting Information), were obtained by integrating the hydrogen underpotential desorption $\left(\mathrm{H}_{\text {upd }}\right)$ peaks of their cyclic voltammograms (CVs) (Figure S5, Supporting Information). ${ }^{41}$ Their ORR polarization curves are shown in Figure If with the half-wave potentials $\left(E_{1 / 2}\right)$ at $0.562 \mathrm{~V}$ (for the fct-FePt/Pt) and $0.533 \mathrm{~V}$ (for the fcc-FePt/ $\mathrm{Pt}$ ). As a comparison, the $E_{1 / 2}$ of the commercial Pt is at 0.531 $\mathrm{V}$, at which the core/shell NPs have a specific activity of 2.1 $\mathrm{mA} / \mathrm{cm}^{2}$ (for the fct-FePt/Pt) and $0.89 \mathrm{~mA} / \mathrm{cm}^{2}$ (for the fcc$\mathrm{FePt} / \mathrm{Pt})$.

Since both fcc-FePt/Pt and fct-FePt/Pt are monodisperse NPs with the same size, shape, $\mathrm{Fe} / \mathrm{Pt}$ ratio, and Pt thickness (ca. three atomic layers of $\mathrm{Pt}$ ), their ORR catalysis difference must originate from structure-induced surface change. To understand this change, we performed QM-MM simulations to calculate $\mathrm{Pt}-\mathrm{O}$ binding energies on the surface of the $\mathrm{FePt}$ / Pt NPs (Supporting Information). The QM-MM modeling combines both the quantum mechanical and classical descriptions, where the QM density functional theory (DFT) is applied to reactive sites to capture chemical reactions, while the long-range strain field of NPs is handled by the classical MM method. ${ }^{42,43}$ As a result, the QM-MM method can treat much larger particle sizes (e.g., $8 \mathrm{~nm}$ ) than previously feasible $(\sim 1 \mathrm{~nm}) \cdot{ }^{44,45}$ We built an $8 \mathrm{~nm}$ cuboctahedral core/shell NP model consisting of $\mathrm{Fe}_{50} \mathrm{Pt}_{50}$ alloy core (fcc- or fct-FePt) and fcc-Pt shell (three atomic layers) (Figure 2a,b). The core/shell $\mathrm{FePt} / \mathrm{Pt} \mathrm{NPs}$ have a theoretical composition of around $\mathrm{Fe}_{25} \mathrm{Pt}_{75}$, consistent with the FePt/Pt NPs studied experimentally. Figure $2 \mathrm{c}$ illustrates atomic configuration of a cuboctahedral NP, which is partitioned to the $\mathrm{QM}$ region and $\mathrm{MM}$ region. By using $\mathrm{QM}-\mathrm{MM}$ and by placing an $\mathrm{O}$ atom at the center of the QM region, we calculated $\Delta E_{\mathrm{O}}$ values of the fcc-FePt/Pt and fct$\mathrm{FePt} / \mathrm{Pt}$ to be 0.26 and $0.23 \mathrm{eV}$, respectively. Commercial $\mathrm{Pt}$ catalyst was also simulated to have a $\Delta E_{\mathrm{O}}$ of $0.1 \mathrm{eV}$ based on the QM-MM method and the $3 \mathrm{~nm} \mathrm{NP}$ model, which was consistent with the previous reported value through DFT calculations. ${ }^{30}$ We can easily expect that a NP catalyst more active than commercial $\mathrm{Pt} \mathrm{NP}$ should possess a $\Delta E_{\mathrm{O}}$ in the range of $0.1-0.3 \mathrm{eV}(0.2 \mathrm{eV}$ is the optimal value). Our fcc$\mathrm{FePt} / \mathrm{Pt}$ and fct-FePt/Pt fall into this regime. As the $\Delta E_{\mathrm{O}}$ value of the fct-FePt/Pt is closer to the optimal value of $0.20 \mathrm{eV}$, the fct-FePt/Pt shows higher ORR activity than the fcc-FePt/Pt.

$\Delta E_{\mathrm{O}}$ is related to the compression (or stretch) of $\mathrm{Pt}$ (i.e., $\mathrm{Pt}$ strain) on the catalyst surface. ${ }^{21}$ In our $\mathrm{FePt} / \mathrm{Pt}$ core/shell structure this strain is caused by the crystal lattice mismatch between the core and the shell. Using the supercell models (Figure 2d,e and Supporting Information) and DFT, we calculated the equilibrium crystalline lattice constants (Table $S 1$, Supporting Information) and the surface Pt strain $(\varepsilon)$ of the fcc- and fct-FePt/Pt and compared them with fcc-Pt (Table 1). 


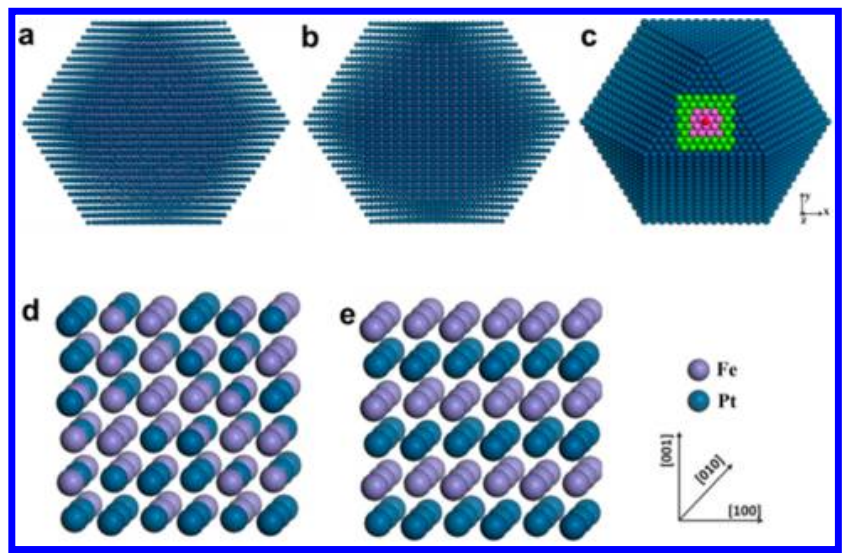

Figure 2. (a, b) Eight nanometer cuboctahedral fcc-FePt/Pt (a) and fct-FePt/Pt (b) core/shell models constructed for QM-MM calculations. Model a contains $7667 \mathrm{Pt}$ atoms and $2512 \mathrm{Fe}$ atoms, and model b consists of $7704 \mathrm{Pt}$ atoms and $2405 \mathrm{Fe}$ atoms. Both models have a core composition of $\mathrm{Fe}_{50} \mathrm{Pt}_{50}$ and a shell of threeatomic-layer Pt. (c) Atomic configuration of a cuboctahedron NP for $\mathrm{QM}-\mathrm{MM}$ calculation, viewing along the $\langle 111\rangle$ direction. The entire system is partitioned into a QM region (red, pink, and green spheres) and a MM region (blue spheres). The red sphere represents the adsorbed $\mathrm{O}$ atom. (d, e) The periodic supercells of fcc- $\mathrm{Fe}_{50} \mathrm{Pt}_{50}(\mathrm{~d})$ and fct- $\mathrm{Fe}_{50} \mathrm{Pt}_{50}$ (e) used to calculate the crystalline lattice constants.

Table 1. Surface Strain $(\varepsilon$, in \%) from DFT Calculations and $\Delta E_{\mathrm{O}}$ from QM-MM Simulations

\begin{tabular}{lcccc}
\multicolumn{1}{c}{ catalyst } & $\varepsilon_{[100]}$ & $\varepsilon_{[010]}$ & $\varepsilon_{[001]}$ & $\Delta E_{\mathrm{O}}(\mathrm{eV})$ \\
$\mathrm{fcc}-\mathrm{FePt} / \mathrm{Pt}$ & 3.9 & 3.6 & 3.5 & 0.26 \\
$\mathrm{fct}-\mathrm{FePt} / \mathrm{Pt}$ & 2.9 & 2.9 & 5.5 & 0.23 \\
$\mathrm{fcc}-\mathrm{FeCuPt} / \mathrm{Pt}$ & 3.3 & 3.7 & 3.3 & 0.25 \\
fct-FeCuPt$/ \mathrm{Pt}$ & 1.4 & 1.5 & 5.0 & 0.22 \\
ideal Pt & & 2.3 & & 0.20
\end{tabular}

Compressive strain is calculated by $\varepsilon_{i}=\left(a_{\mathrm{Pt}}-a_{i}\right) / a_{\mathrm{Pt}}$, where $i$ indicates [100], [010], and [001] directions. $a_{\mathrm{Pt}}$ is the lattice constant of fcc-Pt, and $a_{i}$ is the interplanar distance along the $i$ direction of each core material.

Both fcc- and fct-FePt have smaller lattice constants than Pt, and the corresponding surface $\mathrm{Pt}$ strains are $3 \%-5 \%$, higher than the $2.3 \%$ required for the optimal $\Delta E_{\mathrm{O}}(0.20 \mathrm{eV}) .{ }^{22}$ When the fcc-FePt serves as a core, the surface $\mathrm{Pt}$ is slightly overcompressed $\left(\Delta E_{\mathrm{O}}=0.26 \mathrm{eV}\right)$. But when fcc-FePt transforms to fct-FePt in the core, the interplanar distance of the core expands in the $[100] /[010]$ directions and shrinks in the [001] direction. The overall effect is to relieve the overcompression on the Pt surface, resulting in a better $\Delta E_{\mathrm{O}}$ and higher activity for ORR.

To further improve $\Delta E_{\mathrm{O}}$ by releasing the overcompression on the Pt shell, the fct core structure should be expanded. Our DFT calculations show that when $\mathrm{Fe}$ atoms are substituted partially by $\mathrm{Cu}$ atoms, the lattice constant can be increased (Table S1, Supporting Information). With the similar core/ shell structures, our theoretical models illustrated in Figure 2a,b can be readily extended to FeCuPt (Figure S6, Supporting Information) with the core composition of $\mathrm{Fe}_{25} \mathrm{Cu}_{25} \mathrm{Pt}_{50}$. The $\mathrm{QM}-\mathrm{MM}$ simulations on $\mathrm{FeCuPt} / \mathrm{Pt}$ demonstrated that the $\mathrm{Cu}$ substitution in $\mathrm{FePt}$ could further reduce the overcompression on the $\mathrm{Pt}$ shell (Table 1). As a result, $\Delta E_{\mathrm{O}}$ of the fct-FeCuPt/Pt was reduced to $0.22 \mathrm{eV}$, being the closest to the optimal value in our studied four core/shell NPs. This optimized $\Delta E$ Eo is predicted to give the fct-FeCuPt/Pt the balanced energetics for the adsorption and desorption of oxygenated intermediates, which could further enhance the ORR catalytic performance.

To prove experimentally the effect of $\mathrm{Cu}$ on $\mathrm{Pt}$ strain release and ORR catalysis enhancement, we synthesized fcc-FeCuPt NPs by reacting FePt NPs with $\mathrm{Cu}(\mathrm{acac})_{2}$ and oleylamine in 1octadecene at $240{ }^{\circ} \mathrm{C}$ to facilitate $\mathrm{Cu}(\mathrm{acac})_{2}$ reduction and $\mathrm{Cu}$ diffusion into FePt NPs. The $\mathrm{Cu}$ content was controlled by $\mathrm{FePt} / \mathrm{Cu}(\mathrm{acac})_{2}$ ratios and $\mathrm{Fe}_{38} \mathrm{Cu}_{15} \mathrm{Pt}_{47}, \mathrm{Fe}_{25} \mathrm{Cu}_{23} \mathrm{Pt}_{52}$, and $\mathrm{Fe}_{19} \mathrm{Cu}_{35} \mathrm{Pt}_{46} \mathrm{NPs}$ were synthesized. TEM images show that the FeCuPt NPs have size $\left(8.5 \pm 0.5 \mathrm{~nm}\right.$ for $\mathrm{Fe}_{38} \mathrm{Cu}_{15} \mathrm{Pt}_{47}, 8.6 \pm$ $0.5 \mathrm{~nm}$ for $\mathrm{Fe}_{25} \mathrm{Cu}_{23} \mathrm{Pt}_{52}$, and $8.8 \pm 0.6 \mathrm{~nm}$ for $\left.\mathrm{Fe}_{19} \mathrm{Cu}_{35} \mathrm{Pt}_{46}\right)$ and morphology (cubelike) similar to those of the FePt NPs (Figure $3 \mathrm{a}-\mathrm{c}$ ). Once supported on $\mathrm{C}$ and annealed, these

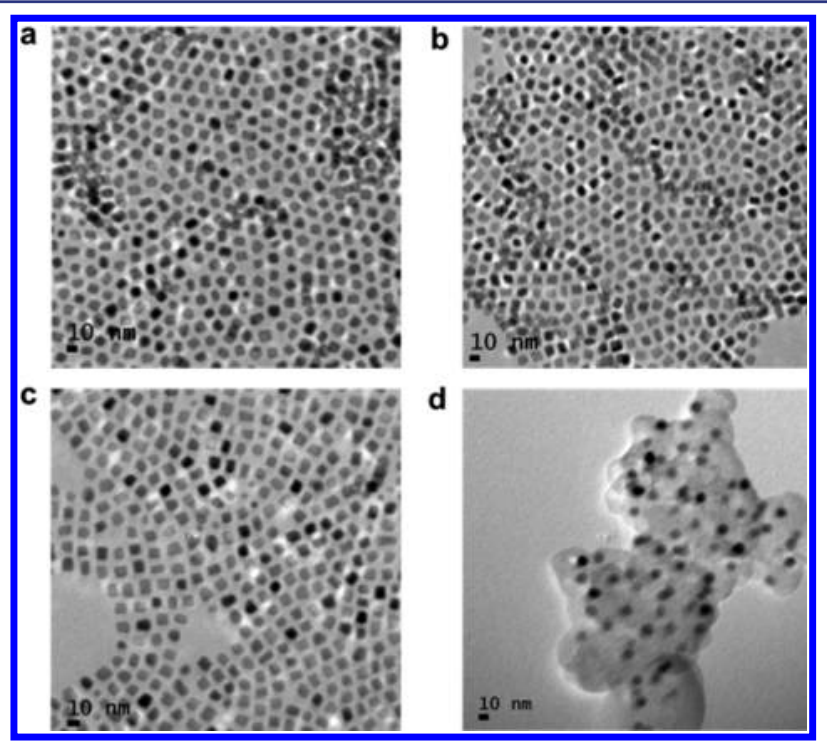

Figure 3. TEM images of the as-synthesized (a) $\mathrm{Fe}_{38} \mathrm{Cu}_{15} \mathrm{Pt}_{47}$, (b) $\mathrm{Fe}_{25} \mathrm{Cu}_{23} \mathrm{Pt}_{52}$, (c) $\mathrm{Fe}_{19} \mathrm{Cu}_{35} \mathrm{Pt}_{46} \mathrm{NPs}$, and (d) the $\mathrm{C}-\mathrm{fct}-\mathrm{Fe}_{25} \mathrm{Cu}_{23} \mathrm{Pt}_{52}$ NPs made from annealing of fcc- $\mathrm{Fe}_{25} \mathrm{Cu}_{23} \mathrm{Pt}_{52} \mathrm{NPs}$ at $650{ }^{\circ} \mathrm{C}$.

FeCuPt NPs were well-dispersed on C (Figure 3d) and showed a Cu-dependent $\mathrm{fcc}-\mathrm{fct}$ transition (Figure 4). At $400{ }^{\circ} \mathrm{C}$, all FeCuPt are still fcc NPs, showing the homogeneous trimetallic

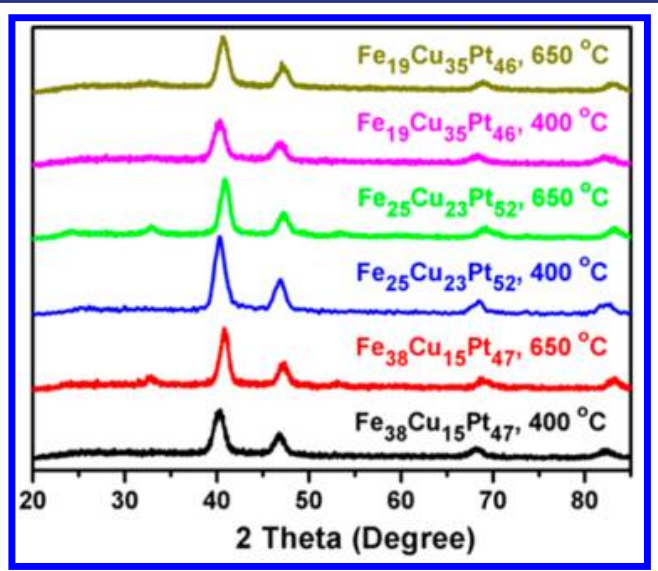

Figure 4. $\mathrm{XRD}$ patterns of the $\mathrm{Fe}_{38} \mathrm{Cu}_{15} \mathrm{Pt}_{47}, \mathrm{Fe}_{25} \mathrm{Cu}_{23} \mathrm{Pt}_{52}$, and $\mathrm{Fe}_{19} \mathrm{Cu}_{35} \mathrm{Pt}_{46} \mathrm{NPs}$ annealed at 400 and $650{ }^{\circ} \mathrm{C}$. The NPs were first deposited on the Ketjen carbon support and then annealed under $95 \%$ $\mathrm{Ar}+5 \% \mathrm{H}_{2}$ for $1 \mathrm{~h}$. 
solid solution structures (Figure 5a). At $650{ }^{\circ} \mathrm{C}$, both $\mathrm{Fe}_{38} \mathrm{Cu}_{15} \mathrm{Pt}_{47}$ and $\mathrm{Fe}_{25} \mathrm{Cu}_{23} \mathrm{Pt}_{52}$ NPs showed better fcc-fct
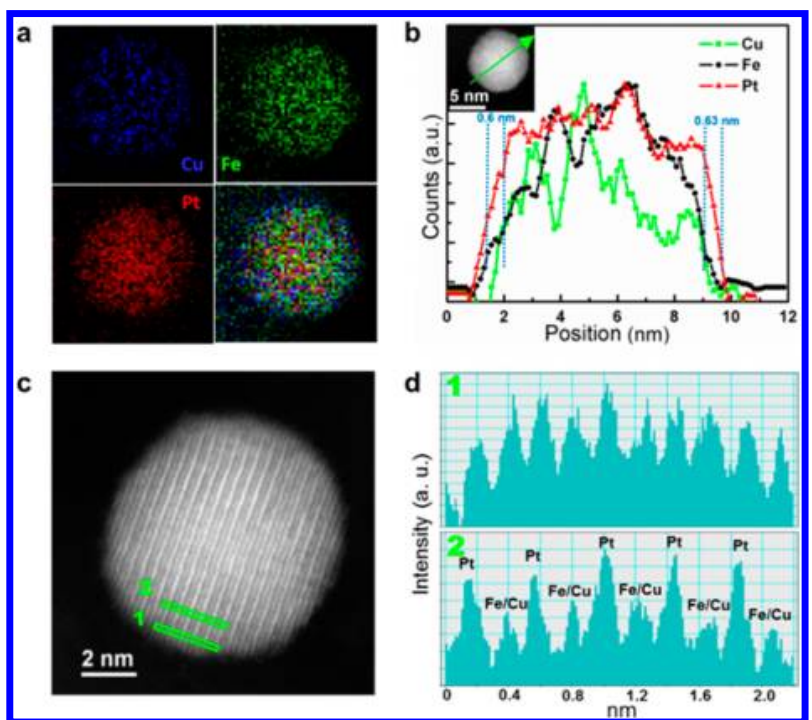

Figure 5. (a) 2D EELS elemental mapping of $\mathrm{Fe}, \mathrm{Cu}$ and $\mathrm{Pt}$ of a fcc$\mathrm{Fe}_{25} \mathrm{Cu}_{23} \mathrm{Pt}_{52} \mathrm{NP}$ annealed at $400{ }^{\circ} \mathrm{C}$, showing a solid solution structure. (b) STEM-EELS line scan crossing a fct-FeCuPt/Pt (dealloyed from fct- $\mathrm{Fe}_{25} \mathrm{Cu}_{23} \mathrm{Pt}_{52}$ ) NP. The inset shows the NP scanned. (c) HAADF-STEM image of a representative fct-FeCuPt/Pt $\mathrm{NP}$ with the indication of two line profiles from the shell and core region. (d) Corresponding HAADF line profile shown in (c) normalized with $Z$ contrast of metal atoms.

transition than the $\mathrm{Fe}_{19} \mathrm{Cu}_{35} \mathrm{Pt}_{46} \mathrm{NPs}$, indicating that the presence of too much $\mathrm{Cu}$ prevents the formation of the fct structure, which is consistent with what has been reported in the thin film studies. ${ }^{46-49}$ The $\mathrm{Fe}_{25} \mathrm{Cu}_{23} \mathrm{Pt}_{52} \mathrm{NPs}$ were found to show the best ORR activity in the current study and were chosen as a representative catalyst to study the effect of $\mathrm{Cu}$ on Pt strain and ORR catalysis.

Similar to the $\mathrm{Fe}_{51} \mathrm{Pt}_{49} \mathrm{NPs}$, the fcc- and fct- $\mathrm{Fe}_{25} \mathrm{Cu}_{23} \mathrm{Pt}_{52}$ $\mathrm{NPs}$ could also be converted into the core/shell $\mathrm{FeCuPt} / \mathrm{Pt}$ with the Pt shell being $\sim 0.6 \mathrm{~nm}$ (ca. three atomic layers) thick, as indicated by STEM-EELS line scans of the $\mathrm{FeCuPt} / \mathrm{Pt}$ structure (Figures $5 \mathrm{~b}$ and S7, Supporting Information). The intermetallic structure, represented by the periodic contrast change in the core region of the fct-FeCuPt/Pt, is clearly visible in the HAADF-STEM image (Figure 5c). HAADF-STEM line scans normalized with $Z$ contrast of different atoms in two different regions on the fct-FeCuPt/Pt NP show the characteristic single-component $\mathrm{Pt}$ shell and intermetallic fct-FeCuPt core (Figure $5 \mathrm{~d}$ ).

Upon comparing the CVs and ORR polarization curves of the $\mathrm{FePt} / \mathrm{Pt}$ with those of the $\mathrm{FeCuPt} / \mathrm{Pt} \mathrm{NPs}$ obtained under the same detection conditions (Figures 6a and S8, Supporting Information), we can see that the ORR curves of the FeCuPt NPs are more positively shifted than those of the FePt NPs. The $E_{1 / 2}$ of the fct-FeCuPt/Pt NPs is at $0.574 \mathrm{~V}$, higher than that of the fct-FePt/Pt NPs at $0.562 \mathrm{~V}$ and commercial $\mathrm{Pt}$ catalyst at $0.531 \mathrm{~V}$. The fct-FeCuPt/Pt NPs have the specific activity of $2.55 \mathrm{~mA} / \mathrm{cm}^{2}$ at $0.531 \mathrm{~V}$, higher than that of fct$\mathrm{FePt} / \mathrm{Pt}\left(2.10 \mathrm{~mA} / \mathrm{cm}^{2}\right)$ (Figure $6 \mathrm{~b}$ ) and almost 10 times higher than that of $\mathrm{Pt}\left(0.264 \mathrm{~mA} / \mathrm{cm}^{2}\right.$ at $\left.0.531 \mathrm{~V}\right)$. The fct$\mathrm{FeCuPt} / \mathrm{Pt} \mathrm{NPs}$ are also extremely durable under the ORR reaction conditions. After 10000 sweeps between 0.4 and $0.7 \mathrm{~V}$

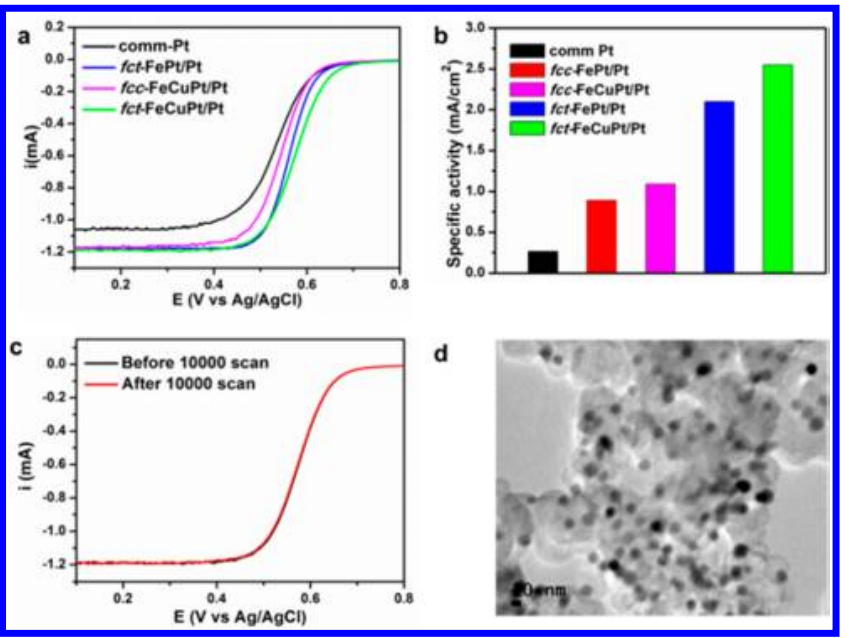

Figure 6. (a) ORR polarization curves of $\mathrm{Pt}$, fct-FePt $/ \mathrm{Pt}$, fcc-FeCuPt/ $\mathrm{Pt}$, and fct-FeCuPt/Pt NPs. (b) The specific activities of the NP catalysts at $0.531 \mathrm{~V}\left(E_{1 / 2}\right.$ of the commercial Pt catalyst). (c) ORR polarization curves of the fct-FeCuPt/Pt NPs before and after 10000 potential scans between 0.4 and $0.7 \mathrm{~V}$. (d) TEM image of the fct$\mathrm{FeCuPt} / \mathrm{Pt} \mathrm{NPs}$ after 10000 potential scans.

in the $\mathrm{O}_{2}$-saturated $0.1 \mathrm{M} \mathrm{HClO}_{4}$, we observed no obvious shift in ORR polarization curves (Figure 6c) and no visible morphology change of NPs (Figure 6d). The fct-FeCuPt/Pt NPs show the best ORR catalytic performance in our experiment, which confirms our theoretical prediction that $\mathrm{Cu}$ substitution can further release the Pt surface strain and indeed enhance the catalytic efficiency of the core/shell NPs for ORR.

\section{CONCLUSION}

The new strategy presented here in tuning Pt shell strain by controlling the FePt structure is a highly efficient way to enhance core/shell FePt/Pt NP catalysis. The FePt/Pt NPs are synthesized by electro-anodization of the FePt alloy NPs. The core FePt structure is controlled to be fcc or fct and the Pt shell is in ca. three atomic layers. The fct-FePt/Pt NPs show much higher activity for ORR than the fcc ones, and the QM-MM simulations reveal that this activity enhancement is due to the release of overcompressed $\mathrm{Pt}$ strain and to the improvement of $\mathrm{Pt}-\mathrm{O}$ binding energy. Our simulations also suggest that the overcompressed strain observed in $\mathrm{FePt} / \mathrm{Pt}$ can be further released when $\mathrm{Fe}$ in the $\mathrm{FePt}$ structure is partially replaced by $\mathrm{Cu}$, and the $\Delta E_{\mathrm{O}}$ of fct-FeCuPt/Pt can reach $0.22 \mathrm{eV}$, which is the closest to the optimal $0.20 \mathrm{eV}$ predicted on a Pt surface. Experimentally, fct-FeCuPt/Pt NPs are indeed the most efficient ORR catalyst, showing nearly 10 times higher specific activity than the benchmark Pt catalyst. Our report offers concrete evidence that surface strain in a core/shell NP can be readily tuned by the core structure to achieve catalytic optimization. The strategy presented here is not limited to $\mathrm{FePt} / \mathrm{Pt} \mathrm{NPs}$ but can be extended to other core/shell NPs as well, providing a novel approach to rational tuning of NP catalytic efficiency for many chemical reactions.

\section{ASSOCIATED CONTENT}

\section{S Supporting Information}

Texts S1 and S2, giving the details of QM-MM simulations and DFT calculations; Table S1, providing the DFT-calculated crystalline lattice constants of all $\mathrm{FePt}$ and $\mathrm{FeCuPt}$ cores; 
Figure S1-S8, giving additional TEM images, HAADF-STEM images, STEM-EELS line scans, CVs, and theoretic models; and Reference $\mathrm{S} 1-\mathrm{S} 10$ for Texts $\mathrm{S} 1$ and S2. This material is available free of charge via the Internet at http://pubs.acs.org.

\section{AUTHOR INFORMATION}

\section{Corresponding Author}

ssun@brown.edu

Notes

The authors declare no competing financial interest.

\section{ACKNOWLEDGMENTS}

This work was supported by the U.S. Army Research Laboratory and the U.S. Army Research Office under the Multi University Research Initiative (MURI, grant number W911NF-11-1-0353) on "Stress-Controlled Catalysis via Engineered Nanostructures”. Electron microscopy work carried out at the Center for Functional Nanomaterials, Brookhaven National Laboratory, was supported by the U.S. Department of Energy, Office of Basic Energy Sciences, under Contract No. DE-AC02-98CH10886.

\section{REFERENCES}

(1) Guo, S.; Zhang, S.; Sun, S. Angew. Chem., Int. Ed. 2013, 52, $8526-8554$.

(2) Yu, W.; Porosoff, M. D.; Chen, J. G. Chem. Rev. 2012, 112, 5780-5817.

(3) Wang, C.; Daimon, H.; Onodera, T.; Koda, T.; Sun, S. Angew. Chem. Int. Ed. 2008, 47, 3588-3591.

(4) Tian, N.; Zhou, Z. Y.; Sun, S. G.; Ding, Y.; Wang, Z. L. Science 2007, 316, 732-735.

(5) Zhu, H.; Zhang, S.; Guo, S.; Su, D.; Sun, S. J. Am. Chem. Soc. 2013, 135, 7130-7133.

(6) Zhu, H.; Zhang, S.; Huang, Y. X.; Wu, L.; Sun, S. Nano Lett. 2013, 13, 2947-2951.

(7) Stamenkovic, V. R.; Mun, B. S.; Arenz, M.; Mayrhofer, K. J. J.; Lucas, C. A.; Wang, G.; Ross, P. N.; Markovic, N. M. Nat. Mater. 2007, 6, 241-247.

(8) Cargnello, M.; Doan-Nguyen, V. V. T.; Gordon, T. R.; Diaz, R. E.; Stach, E. A.; Gorte, R. J.; Fornasiero, P.; Murray, C. B. Science 2013, 341, 771-773.

(9) Stamenkovic, V. R.; Fowler, B.; Mun, B. S.; Wang, G.; Ross, P. N.; Lucas, C. A.; Markovic, N. M. Science 2007, 315, 493-497.

(10) Tedsree, K.; Li, T.; Jones, S.; Chan, C. W. A.; Yu, K. M. K.; Bagot, P. A. J.; Marquis, E. A.; Smith, G. D. W.; Tsang, S. C. E. Nat. Nanotechnol. 2011, 6, 302-307.

(11) Lim, B.; Jiang, M.; Camargo, P. H. C.; Cho, E. C.; Tao, J.; Lu, X.; Zhu, Y.; Xia, Y. Science 2009, 324, 1302-1305.

(12) Zhang, J.; Mo, Y.; Vukmirovic, M. B.; Klie, R.; Sasaki, K.; Adzic, R. R. J. Phys. Chem. B 2004, 108, 10955-10964.

(13) Snyder, J.; Fujita, T.; Chen, M. W.; Erlebacher, J. Nat. Mater. 2010, 9, 904-907.

(14) Zhang, J.; Yang, H.; Fang, J.; Zou, S. Nano Lett. 2010, 10, 638644.

(15) Wang, C.; Chi, M.; Li, D.; Strmcnik, D.; Vliet, D. V. D; Wang, G.; Komanicky, V.; Chang, K. C.; Paulikas, A. P.; Tripkovic, D.; Pearson, J.; More, K. L.; Markovic, N. M.; Stamenkovic, V. R. J. Am. Chem. Soc. 2011, 133, 14396-14403.

(16) Zhang, J.; Sasaki, K.; Sutter, E.; Adzic, R. R. Science 2007, 315, 220-222.

(17) Cui, C.; Gan, L.; Heggen, M.; Rudi, S.; Strasser, P. Nat. Mater. 2013, 12, 765-771.

(18) Lu, Y. C.; Xu, Z.; Gasteiger, H. A.; Chen, S.; Hamad-Schifferli, K.; Yang, S. H. I. Am. Chem. Soc. 2010, 132, 12170-12171.

(19) Cui, C.; Yu, S.-H. Acc. Chem. Res. 2013, 46, 1427-1437.
(20) Cui, C.; Li, H.-H.; Liu, X.-J.; Gao, M.-R.; Yu, S.-H. ACS Catal. 2012, 2, 916-924.

(21) Mavrikakis, M.; Hammer, B.; Norskov, J. K. Phys. Rev. Lett. 1998, 81, 2819-2822.

(22) Nilsson, A.; Pettersson, L. G. M.; Norskov, J. K. Chemical Bonding at Surfaces and Interfaces. Elsevier: Amsterdam, 2008.

(23) Adzic, R. R.; Zhang, J.; Sasaki, K.; Vukmirovic, M. B.; Shao, M.; Wang, J. X.; Nilekar, A. U.; Mavrikakis, M.; Uribe, F. Top. Catal. 2007, 46, 249-262.

(24) Yang, R.; Leisch, J.; Strasser, P.; Toney, M. F. Chem. Mater. 2010, 22, 4712-4720.

(25) Strasser, P.; Koh, S.; Anniyev, T.; Greeley, J.; More, K. L.; Yu, C.; Liu, Z.; Kaya, S.; Nordlund, D.; Ogasawara, H.; Toney, M. F.; Nilsson, A. Nat. Chem. 2010, 2, 454-460.

(26) Yang, J.; Yang, J.; Ying, J. Y. ACS Nano 2012, 6, 9373-9382.

(27) Wu, J.; Qi, L.; You, H.; Gross, A.; Li, J.; Yang, H. J. Am. Chem. Soc. 2012, 134, 11880-11883.

(28) Norskov, J. K.; Rossmeisl, J.; Logadottir, A.; Lindqvist, L.; Kitchin, J. R.; Bligaard, T.; Jonsson, H. J. Phys. Chem. B 2004, 108, 17886-17892.

(29) Stamenkovic, V. R.; Mun, B. S.; Mayrhofer, K. J. J.; Ross, P. N.; Markovic, N. M.; Rossmeisl, J.; Greeley, J.; Nørskov, J. K. Angew. Chem. Int. Ed. 2006, 45, 2897-2901.

(30) Li, L.; Larsen, A. H.; Romero, N. A.; Morozov, V. A.; Glinsvad, C.; Abild-Pedersen, F.; Greeley, J.; Jacobsen, K. W.; Nørskov, J. K. J. Phvs. Chem. Lett. 2013, 4, 222-226.

(31) Qi, L.; Li, J. L. Catal. 2012, 295, 59-69.

(32) Zhang, S.; Guo, S.; Zhu, H.; Su, D.; Sun, S. J. Am. Chem. Soc. 2012, 134, 5060-5063.

(33) Chen, H.; Wang, D.; Yu, Y.; Newton, K. A.; Muller, D. A.; Abruña, H. D.; DiSalvo, F. J. I. Am. Chem. Soc. 2012, 134, 1845318459.

(34) Wang, D.; Xin, H. L.; Hovden, R.; Wang, H.; Yu, Y.; Muller, D. A.; DiSalvo, F. J.; Abruña, H. D. Nat. Mater. 2013, 12, 81-87.

(35) Prabhudev, S.; Bugnet, M.; Bock, C.; Botton, G. A. ACS Nano 2013, 7, 6103-6110.

(36) Sun, S.; Murray, C. B.; Weller, D.; Folks, L.; Moser, A. Science 2000, 287, 1989-1992.

(37) Sun, S. Adv. Mater. 2006, 18, 393-403.

(38) Kim, J.; Rong, C.; Liu, J. P.; Sun, S. Adv. Mater. 2009, 21, 906909.

(39) Zhang, S.; Onder, M.; Su, D.; Sun, S. Angew. Chem., Int. Ed. 2013, 52, 3681-3684.

(40) Crewe, A. V.; Wall, J.; Langmore, J. Science 1970, 168, 13381340.

(41) Guo, S.; Zhang, S.; Su, D.; Sun, S. J. Am. Chem. Soc. 2013, 135, 13879-13884.

(42) Zhang, X.; Lu, G.; Curtin, W. A. Phvs. Rev. B 2013, 87, $054113-$ 054122 .

(43) Froemming, N. S.; Henkelman, G. I. Chem. Phys. 2009, 131, 234103-234109.

(44) Zhang, X.; Lu, G. I. Phys. Chem. Lett. 2014, 5, 292-297.

(45) Tang, W.; Henkelman, G. I. Chem. Phvs. 2009, 130, 194504194509.

(46) Kai, T.; Maeda, T.; Kikitsu, A.; Akiyama, J.; Nagase, T.; Kishi, T. I. Appl. Phvs. 2004, 95, 609-612.

(47) Takahashi, Y. K.; Ohnuma, M.; Hono, K. J. Magn. Magn. Mater. 2002, 246, 259-265.

(48) Sun, X. C.; Kang, S.; Harrell, J. W.; Nikles, D. E.; Dai, Z. R.; Li, J.; Wang, Z. L. I. Appl. Phvs. 2003, 93, 7337-7339.

(49) Gilbert, D. A.; Wang, L. W.; Klemmer, T. J.; Thiele, J. U.; Lai, C. H.; Liu, K. Appl. Phys. Lett. 2013, 102, 132406-132409. 